\title{
УДК 342.572
}

\section{ЧТО ИЗМЕНИЛОСЬ ДЛЯ СФЕРЫ КУЛЬТУРЫ ПОСЛЕ ВНЕСЕНИЯ ПОПРАВОК В КОНСТИТУЦИЮ РОССИИ: ИННОВАЦИИ ГЛАВНОГО ЗАКОНА СТРАНЫ В РЕАЛЬНОСТИ}

Орлова Мария Александровна GR-директор представительства медиахолдинга «Актион МЦФЭР» в Алтайском крае, магистрант РАНХиГС, ИГСУ

Аннотация: В июле 2020 года вступили в силу поправки в Конституцию Российской Федерации, в том числе затрагивающие сферу культуры, среди которых закрепление обязанности государства поддерживать и охранять культуру. Опираясь на данные нормы, в декабре 2020 года автор выступил с законодательными инициативами, помогающими в работе учреждений культуры. Автор делится этим опытом и предлагает читателям самостоятельно оценить, насколько работают новые нормы Конституции России на практике.

Ключевые слова: Конституция Российской Федерации, поправки в Конституцию Российской Федерации, сфера культуры, учреждения культуры, культурно-досуговые учреждения, налог на прибыль, институты гражданского общества, непосредственное законотворчество народа, право народа на законодательную инициативу.

\section{WHAT HAS CHANGED FOR THE CULTURAL SPHERE AFTER THE AMENDMENTS TO THE CONSTITUTION OF RUSSIA: INNOVATIONS OF THE MAIN LAW OF THE COUNTRY IN REALITY}

\begin{abstract}
In July 2020, amendments to the Constitution of the Russian Federation entered into force, including those affecting the sphere of culture, including the consolidation of the state's obligation to maintain and protect culture. Based on these norms, in December 2020, the author made legislative initiatives to help in the work of cultural institutions. The author shares this experience and invites readers to independently assess how the new norms of the Russian Constitution work in practice.

Key words: The Constitution of the Russian Federation, amendments to the Constitution of the Russian Federation, the sphere of culture, cultural institutions,
\end{abstract}


cultural and leisure facilities, income tax, civil society institutions, direct law-making of the people, the right of the people to legislative initiative.

\section{Нормы Конституции России, касающиеся сферы культуры}

С 4 июля 2020 года вступили в силу поправки в Конституцию Российской Федерации, в том числе затрагивающие и область культуры [2], [3]. Автор работы считает принципиально значимым изменением дополнение статьи 68 Конституции России частью 4, в которой закреплена обязанность государства поддерживать и охранять культуру.

Прямые конституционные нормы, касающиеся сферы культуры, представлены в таблице. В таблице отмечено, какие из 14-ти перечисленных норм были скорректированы.

Таблица

Нормы Конституции РФ, касающиеся сферы культуры

\begin{tabular}{|c|c|c|}
\hline $\begin{array}{c}\text { № } \\
\text { пI/II }\end{array}$ & О чем говорится в норме & $\begin{array}{c}\text { Норма } \\
\text { Конституции } \\
\text { РФ [1] }\end{array}$ \\
\hline 1 & $\begin{array}{l}\text { Россия - социальное государство, политика которого направлена } \\
\text { на создание условий, обеспечивающих достойную жизнь и } \\
\text { свободное развитие человека }\end{array}$ & Ч. 1 ст. 7 \\
\hline 2 & $\begin{array}{l}\text { Каждый имеет право на свободный выбор языка общения, } \\
\text { воспитания, обучения и творчества }\end{array}$ & Ч. 2 ст. 26 \\
\hline 3 & $\begin{array}{l}\text { Каждому гарантируется свобода литературного, } \\
\text { художественного, научного, технического и других видов } \\
\text { творчества, преподавания. Интеллектуальная собственность } \\
\text { охраняется законом }\end{array}$ & Ч. 1 ст. 44 \\
\hline 4 & $\begin{array}{l}\text { Каждый имеет право на участие в культурной жизни и } \\
\text { пользование учреждениями культуры, на доступ к культурным } \\
\text { ценностям }\end{array}$ & Ч. 2 ст. 44 \\
\hline 5 & $\begin{array}{l}\text { Каждый обязан заботиться о сохранении исторического и } \\
\text { культурного наследия, беречь памятники истории и культуры }\end{array}$ & Ч. 3 ст. 44 \\
\hline 6 & $\begin{array}{l}\text { Культура в Российской Федерации является уникальным } \\
\text { наследием ее многонационального народа. Культура } \\
\text { поддерживается и охраняется государством } \\
\text { (норма введена } 4 \text { июля } 2020 \text { года) }\end{array}$ & Ч. 4 ст. 68 \\
\hline 7 & $\begin{array}{l}\text { Государство защищает культурную самобытность всех народов } \\
\text { и этнических общностей России, гарантирует сохранение } \\
\text { этнокультурного и языкового многообразия } \\
\text { (норма введена } 4 \text { июля } 2020 \text { года) }\end{array}$ & Ч. 2 ст. 69 \\
\hline
\end{tabular}




\begin{tabular}{|c|c|c|}
\hline 8 & $\begin{array}{l}\text { Российская Федерация оказывает поддержку соотечественникам, } \\
\text { проживающим за рубежом, в осуществлении их прав, } \\
\text { обеспечении защиты их интересов и сохранении } \\
\text { общероссийской культурной идентичности } \\
\text { (норма введена } 4 \text { июля } 2020 \text { года) }\end{array}$ & Ч. 3 ст. 69 \\
\hline 9 & $\begin{array}{l}\text { Основы федеральной политики и федеральные программы в } \\
\text { области культурного развития России устанавливает Российская } \\
\text { Федерация }\end{array}$ & Ч. «е» ст. 71 \\
\hline 10 & $\begin{array}{l}\text { Охрана памятников истории и культуры находится совместном } \\
\text { ведении Российской Федерации и субъектов РФ }\end{array}$ & $\begin{array}{c}\text { П. «Д》 ч. } 1 \text { ст. } \\
72\end{array}$ \\
\hline 11 & $\begin{array}{l}\text { Общие вопросы воспитания, образования, науки, культуры } \\
\text { находятся в совместном ведении Российской Федерации и } \\
\text { субъектов РФ }\end{array}$ & $\begin{array}{l}\text { П. «е» ч. } 1 \text { ст. } \\
72\end{array}$ \\
\hline 12 & $\begin{array}{l}\text { Для охраны культурных ценностей могут вводиться ограничения } \\
\text { перемещения товаров и услуг в соответствии с федеральным } \\
\text { законом }\end{array}$ & Ч. 2 ст. 74 \\
\hline 13 & $\begin{array}{l}\text { Проведение в России единой социально ориентированной } \\
\text { государственной политики в области культуры, науки, } \\
\text { образования, здравоохранения, социального обеспечения, } \\
\text { поддержки, укрепления и защиты семьи, сохранения } \\
\text { традиционных семейных ценностей, а также в области } \\
\text { охраны окружающей среды обеспечивает Правительство РФ } \\
\text { (формулировка в редакции от } 4 \text { июля } 2020 \text { года) }\end{array}$ & $\begin{array}{c}\text { П. «в» ч. } 1 \text { ст. } \\
114\end{array}$ \\
\hline 14 & $\begin{array}{l}\text { Условия для развития системы экологического образования } \\
\text { граждан, воспитания экологической культуры создает } \\
\text { Правительство РФ } \\
\text { (норма введена } 4 \text { июля } 2020 \text { года) }\end{array}$ & $\begin{array}{l}\text { П. «е.6» ч. } 1 \text { ст. } \\
114\end{array}$ \\
\hline
\end{tabular}

Таким образом, в Конституции Российской Федерации прямо закреплено, что культура в России - уникальное народное наследие. Государство обязано поддерживать и охранять культуру. Российская Федерация устанавливает основы федеральной политики и федеральные программы в области культурного развития России. А вот общие вопросы воспитания и культуры находятся в совместном ведении России и субъектов Российской Федерации. За проведение единой государственной политики в области культуры отвечает Правительство РФ, при этом подчеркивается, что она должна быть социально ориентированной.

Также можно отметить, что в Конституцию России внесли поправки, которыми закрепили значимость семьи, семейных ценностей, их сохранения и защиты. В целом вектор укрепления институтов семьи и брака прослеживается 
и в документах стратегического развития, в том числе в национальных проектах.

Анализируя поправки в Конституцию России, Зотов А.Д. и Кузнецова А.С. в своем исследовании к особенностям принятия поправок относят дублирование норм отраслевых кодифицированных или специализированных актов, которые уже имеют правовое значение, юридическую силу на территории России и необходимость повторного закрепления в Конституции РФ отсутствует [6]. В частности социальных гарантий, которые и так закреплены в федеральных законах. Однако к вышеуказанным нормам о культуре, по мнению автора, это не относится.

Проблемы сферы культуры и их решение до и после принятия поправок в Конституцию России

В 2017-2020 года автор работал главным редактором электронной справочной системы «Культура». В этой должности с 2019 года автор помогал освободить от налога на прибыль культурно-досуговые учреждения. С 1 января 2020 года вступила в силу статья 284.8 Налогового кодекса РФ, на основании которой государственные и муниципальные музеи, театры, библиотеки получили право применять ставку 0\% по налогу на прибыль. Это возможно в отношении деятельности, включенной в Перечень видов культурной деятельности, установленный Правительством РФ. Автор совместно с активными представителями культурно-досуговых учреждений добивался распространения ставки 0\% по налогу на прибыль на культурно-досуговые учреждения.

Стратегия государственной культурной политики до 2030 года предусматривает многоканальную систему финансирования отрасли, в том числе развитие платных услуг [4]. Национальный проект «Культура» предусматривает увеличение посещаемости платных мероприятий культурнодосуговых учреждений на 15\% [5]. Введение нулевой ставки по налогу на прибыль будет дополнительно способствовать решению этих задач.

В 2012 году Владимир Мединский в должности Министра культуры РФ говорил, что отрасль культуры должна быть в приоритете и пользоваться соответствующими финансовыми льготами. А своей задачей на этом посту, помимо менеджмента, называл «лоббист, защитник интересов отрасли в правительстве, в руководстве страны и в обществе» [7]. Владимир Ростиславович поддерживал закон об освобождении всех учреждений культуры от налога на прибыль: «Мы решили точечно решать практические проблемы, которые стоят перед отраслью и перед работниками этой отрасли. Например, 
сейчас находится в финальной стадии согласования закон об освобождении всех учреждений культуры от налога на прибыль. Bcex, я подчеркну, даже частных. Мы считаем, что отрасль должна быть в приоритете и пользоваться соответствующими финансовыми льготами... За исключением кинотеатров» [7]. Однако данный законопроект так и не стал законом.

Впервые вопрос о нулевой ставке для культурно-досуговых учреждений автор поднял на личном приеме у Владимира Мединского 20 декабря 2019 года, который он вел прием в Правительстве РФ в должности Министра культуры РФ. Он сказал: «Это интересные вопросы, мы обязательно ими займемся» данная информация размещена на сайте Минкультуры России [8]. Также Министр культуры РФ сказал, что если автора не устроит результат, он может обратиться повторно и он готов его принять еще раз. По итогам приема Владимир Мединский дал поручения своим заместителям со сроком исполнения один месяц. Однако после роспуска Правительства РФ 15 января 2020 года поручение по этому вопросу фактически оставили без исполнения.

Год спустя - 22 декабря 2020 года, после принятия поправок в Конституцию России, для решения названной проблемы автор вновь обратился к Владимиру Мединскому уже как к Помощнику Президента Российской Федерации. В тексте обращения автор сослался на итоги личного приема у Министра культуры РФ в 2019 году и расписанные им на заместителей поручения. В обращении автор в рамках государственной поддержки культуры, гарантированной Конституцией России, просил Владимира Ростиславовича повторно содействовать решению проблем учреждений культуры, которые препятствуют достижению национальных целей развития Российской Федерации до 2030 года, обозначенных Указом Президента РФ от 21.07.2020 № 474, и целевых показателей национального проекта «Культура», и обсудить возможные пути их решения. Для обсуждения вышеизложенных вопросов и возможности выстроить конструктивное сотрудничество, которое поможет учреждениям культуры работать в новых условиях и достигать поставленных национальных целей, автор просил принять его лично оффлайн или дистанционно с использованием средств конференц-видеосвязи.

Обращение автора не было доставлено адресату - его перевели на Министерство культуры РФ, которое в ответ на обращение направило автору по электронной почте письмо от 14.01.2021 № 63-05-08 следующего содержания.

«Уважаемая Мария Александровна! 
Департамент музеев и внешних связей Минкультуры России в ответ на Ваше обращение, поступившее из Управления Президента Российской Федерации по работе с обращениями граждан и организаций, сообщает следующее.

Минкультуры высоко оценивает Вашу озабоченность достижением целей национального развития Российской Федерации до 2030 года, сформулированных в Указе Президента Российской Федерации от 21.07.2021 № 474, а также национального проекта «Культура».

В настоящее время, принимая во внимание осложнение эпидемиологической обстановки, сопряженной с высоким риском инфицирования COVID-19, срок общероссийского дня приема граждан, ранее запланированный на 14.12.2020, отложен до стабилизации эпидемиологической ситуации.

Дополнительно информируем, что в соответствии с Методическими рекомендациями по режиму труда органов государственной власти, органов местного самоуправления и организаций с участием государства, разработанными Министерством труда и социальной защиты Российской Федерации от 16.03.2020 № 19-0/10/П-2261, а также п.2.8 Плана неотложных мероприятий по предупреждению распространения коронавирусной инфекции (COVID-19), утвержденного приказом Минкультуры России от 19.03.2020 № 379, в Минкультуры России временно ограничен личный прием граждан.

Данная информация размещена на официальном сайте Минкультуры России (www.mkrf.ru).

Принимая во внимание изложенное, проведение личного приема для обсуждения путей решения обозначенных Вами проблем в ближайшее время не представляется возможным».

\section{Выводы}

Изменение Конституции России и усиление в ней роли культуры, а также закрепление гарантии государства поддерживать культуру никак не повлияли на реальную ситуацию в сфере культуры. Из вышеприведенного текста ответа Минкультуры России неясно, что мешает обсудить проблему и найти решение по видеосвязи. В этом формате Президент России и Правительство РФ работают почти год, в том числе проводят совещания, в котором участвуют представители Минкультуры России.

Таким образом, в головах чиновников все осталось по прежнему, принцип «нет поручения - нет проблемы» сохраняется, ответ на любое обращение фактически является отпиской. Поэтому пока сверху до чиновников 
не донесут информацию, что государство и граждане идут единым курсом, направленным на достижение общих национальных целей, пока не изменится их сознание, достичь стратегических целей развития России не получится.

\section{Список литературы}

1. Конституция Российской Федерации с внесенными поправками от 14.03.2020//Официальный интернет-портал правовой информации http://www.pravo.gov.ru, 04.07.2020.

2. Закон РФ о поправке к Конституции РФ от 14.03.2020 № 1-ФКЗ «О совершенствовании регулирования отдельных вопросов организации и функционирования публичной власти»//Официальный интернет-портал правовой информации http://www.pravo.gov.ru, 14.03.2020.

3. Указ Президента РФ от 03.07.2020 № 445 «Об официальном опубликовании Конституции Российской Федерации с внесенными в нее поправками»//Официальный интернет-портал правовой информации http://www.pravo.gov.ru, 03.07.2020.

4. Распоряжение Правительства РФ от 29.02.2016 № 326-р «Об утверждении Стратегии государственной культурной политики на период до 2030 года»//Официальный интернет-портал правовой информации http://www.pravo.gov.ru, 04.03.2016.

5. Паспорт национального проекта «Культура» (утв. президиумом Совета при Президенте РФ по стратегическому развитию и национальным проектам, протокол от 24.12.2018 № 16).

6. Зотов А.Д., Кузнецова А.С. «Особенности поправок в Конституцию Российской Федерации 2020 года»// Киберюрист. - 2020. - № 5 - С. 39-49.

7. Стенограмма онлайн-интервью с Министром культуры РФ В.Р. Мединским в редакции «Газеты.ру» от 10.10.2012: «Я рассматриваю себя как управленца в сфере культуры» // https://www.gazeta.ru/ interview/nm/s4801185.shtml

8. Информационное сообщение на сайте Минкультуры РФ от 20.12.2019 по итогам личного приема граждан Министром культуры РФ Мединским В.Р. в Правительстве РФ «Владимир Мединский поддержал инициативу создания первого в РФ Музея подземной архитектуры»// https://culture.gov.ru/ press/news/vladimir_medinskiy_vstretilsya_s_diggerami_i_obsudil_sozdanie_pervog o_v_rf_muzeya_podzemnoy_arkhitek/ 